\title{
Postoperative Vomiting as a Complication for Laparoscopic Bariatric Surgeries: A Retrospective Study
}

\author{
M. A. Marzouk, W. Ibrahim, Amr H. Afifi, Rania Elahmady \\ Department of General Surgery, Ain Shams University, Egypt
}

Introduction: Vomiting is a postoperative complication in all bariatric surgical interventions since the focus of the procedure is related to the stomach, research efforts are required to reveal the best management course for this issue.

Aim of the work: The primary study objective is to assess the percentage of postoperative vomiting occurrence after laparoscopic bariatric surgeries for two months, its causes with investigations and ways of management.

Patients and methods: The current research study is a retrospective clinical research trial that recruited 100 cases. All study subjects have undergone Laparoscopic Bariatric Surgeries over a 6 months period in Ain Shams University Hospitals during the period from December 2017 to June 2018.

Results: A large percentage of patients (39\%) developed Postoperative Vomiting during the first 48 postoperative hours. While (4\%) of cases who continued to suffer from Vomiting during the postoperative 2 months.

Conclusions: Postoperative vomiting after Laparoscopic Bariatric Surgeries (LBS) represents a considerable complication which occurs commonly. Vomiting of medical causes responds well to centrally acting antiemetic and to a lesser extent, endoscopic and surgical interventions were required for technical problems.

\section{Introduction}

Obesity is a global epidemic with rising comorbidities and reduced life expectancy. Obesity is best managed by weight losing surgical interventions resulting in long term curative weight loss aiding in reduction and resolution of associated comorbidities such as hypertension and DM. ${ }^{1-3}$

Bariatric surgeries are classified into restrictive or malabsorptive surgical interventions or a conjunction of both. Bariatric surgeries are improved by time to ensure high safe profiles with desired favourable clinical outcomes. Cases having a BMI $\geq 40 \mathrm{~kg} / \mathrm{m} 2$ and those with BMI $>35 \mathrm{~kg} / \mathrm{m} 2$ with obesity linked comorbidities; in which management with diet have failed, besides exercise, and drug therapy, should be counselled and considered to be prepared properly for bariatric surgical intervention. ${ }^{4-6}$

Vomiting is a postoperative complication in all bariatric surgical interventions since the focus of the procedure is related to the stomach, so during the recovery process, it is common that there will be some discomfort in this area. It could be medical (e.g. due anaesthetics and stress gastritis) or technical (e.g.; blood clot, kinking, obstruction and adhesions).Vomiting is often triggered by different things, such as anxiety, illness, perioperative stimuli, anesthesia, drug interactions, marginal ulceration, staple line failure, stenosis/obstruction, gastrogastric fistula, gastrojejunostomy anastomotic stricture, pouch dilation, and pouch gastritis. ${ }^{7-10}$
Anatomical aberrations in the shape or position of the stomach may cause postoperative vomiting. Abnormal position of the stomach along its longitudinal axis is due to mal-rotation of the GIT that occurs in an early stage of the prenatal life. They include: Lack, incomplete or over-rotation of the stomach. Abnormal positions among horizontal axis contains gastric cascades characterized by a biloculation of the gastric cavity into a ventral (corpus and antrum) and a dorsal (fundus) recess. These aberrations may be congenital, functional or secondary to organic disorders of the stomach and surrounding organs, mostly peritoneal adhesions. ${ }^{11}$

Congenital aberrations in the shape of the stomach includes absence of the whole organ, absence of the fundus, short body, long pyloric canal and organ dilatation. Stomach shape may be also affected by the feeding habits. Persistent intake of large amount of food may increase the organ volume. ${ }^{11}$

\section{Aim of the work}

The aim in the current study is to evaluate the percentage of postoperative vomiting occurrence after laparoscopic bariatric surgeries for two months, its causes either medical or technical during operation with investigations and ways of management.

\section{Patients and methods}

The current research study is a retrospective clinical research trial that recruited 100 cases. 
All study subjects have undergone Laparoscopic Bariatric Surgeries over a 6 months period in Ain Shams University Hospitals during the period from December 2017 to June 2018. Preoperative evaluation followed the same standard protocol and included an accurate personal, medical and surgical history, complete endocrinal workup and psychological testing. All patients underwent a standard evaluation preoperatively concerning $\mathrm{H}$-pylori test using non-invasive $\mathrm{H}$-pylori antigen rapid test in stool patients who render positive for $\mathrm{H}$-pylori took the triple therapy treatment: Proton Pump Inhibitor (Pantoprazole $40 \mathrm{mg}$ twice daily), amoxicillin (1 g twice daily), and clarithromycin (500 mg twice daily) for 2 weeks preoperatively.

Blood tests were requested in the form of complete blood picture, Fasting blood sugar, Lipid profile (cholesterol, LDL, HDL, triglycerides) Clinical chemistries (serum albumin, ALT, AST, GGT, Urea, Creatinine), pregnancy test for female patients, Viral markers (HBs Ag., HCV Ab.), Prothrombin time (PT) and Partial thromboplastin time (PTT). Abdominal sonography, chest $\mathrm{X}$-ray were performed preoperatively. Thromboembolic prophylaxis with subcutaneous low molecular weight heparin was administered on the evening prior to surgery and continued daily from the first postoperative day till one week postoperatively. Comorbidities that increase perioperative risk as hypertension and Diabetes were controlled before surgery.

Informed written consent was obtained with explanation of the possible complications that could occur in the peri-operative period was specifically addressed. All patients were informed about the nature of the research, and each patient understood and agreed to the procedure after approval obtained from the Research Ethical Committee of the department of General surgery, Faculty of Medicine, Ain Shams University.

Inclusive research Criteria involved the following, morbidly obese patients between 18-55 years old willing and able to give consent. Cases of both genders (male and female). Cases having BMI (> 40 $\mathrm{kg} / \mathrm{m} 2)$ or BMI (35-39.9 kg/m2) with comorbidities like hypertension and diabetes. Cases generally fit for anaesthesia and surgery. Non-surgical methods have been tried but have failed to achieve or maintain adequate, clinically beneficial weight loss for at least six months. Exclusive research criteria, extremities of age, BMI above $55 \mathrm{~kg} / \mathrm{m} 2$, pregnancy or lactation at screening for surgery, previous malabsorptive or restrictive procedures performed for the treatment of obesity.

Postoperative regimen: Patients were encouraged to move out of bed few hours after surgery, Anticoagulation DVT prophylaxis (enoxaparin 40 IU/ day S.C) was given till one week postoperative. We start administration of IV PPI from first postoperative day, which is continued orally after patients start oral feeding. All patients received IV antiemetic every 12 hours till discharge.

Patients began oral fluid intake on the first postoperative day. A post-surgical diet progression from liquids to solids during 6 to 8 weeks with focus on meeting protein, fluid needs, and additional daily micronutrient supplements intake was advised for all patients. Patients were advised to have liquid diet for the first 15 days followed by ground foods until the first postoperative month. Since then, they were encouraged to eat soft solids and to gradually proceed to regular food. They were also advised to eat frequent meals in small portions and consume all types of foods with the exception of high sugar and fatty foods.

\section{Follow-up and Data Collection}

All patients were followed up for early post-operative complications like bleeding, leakage, vomiting and superficial or deep infections.

\section{Statistical analysis}

Inferential analyses were done for quantitative variables using independent t-test in cases of two independent groups, ANOVA test for more than two independent groups with post hoc Tuky's test. In qualitative data, inferential analyses for independent variables were done using Chi square test for differences between proportions and Fisher's Exact test for variables with small expected numbers. Logistic regression was done for factors affecting clinical and completed first trimester pregnancy among the studied cases. The level of significance was taken at $P$ value $<0.050$ is significant, otherwise is non-significant.

\section{Results}

This retrospective study included 100 patients presented with morbid obesity with BMI range between (37.9 to $55 \mathrm{~kg} / \mathrm{m} 2$ ) who were treated surgically by Laparoscopic Bariatric Surgeries in Ain Shams University Hospitals during the period from December 2017 to June 2018.

\section{The results of this study are recorded as following:}

\section{A. Demographic distribution of patients:}

Before surgery patients were categorized according to sex, age, BMI, special habits of medical importance, comorbidities and evidence of $\mathrm{H}$-pylori infection. Female to male ratio being $5: 1$, with most patients between $31-40$ years old (32\%) followed by $18-30$ years old $(29 \%)$ and $41-50$ years old $(28 \%)$. The highest percentage of patients lies in the BMI range of $45-49.9 \mathrm{~kg} / \mathrm{m} 2$ (38\%) followed by $40-44.9$ $\mathrm{kg} / \mathrm{m} 2(29 \%)$ and $50-55 \mathrm{~kg} / \mathrm{m} 2(28 \%)$. The majority 
of patients were non-smokers ( $86 \%$ ) vs smokers $(14 \%) .75 \%$ of patients had no comorbidities while (9\%) were diabetic, $(13 \%)$ were hypertensive and
(3\%) were asthmatic. After searching for $\mathrm{H}$-pylori antigen in stool $(74 \%)$ rendered negative where (26\%) were marked positive by the test (Table 1).

Table 1: Demographic distribution of patients

\begin{tabular}{|c|c|c|c|}
\hline Demographic & Distribution & No. of patients & Percentage \% \\
\hline \multirow{2}{*}{ Sex } & Male & 15 & $15 \%$ \\
\hline & Female & 85 & $85 \%$ \\
\hline \multirow{4}{*}{ Age } & $18-30$ & 29 & $29 \%$ \\
\hline & $31-40$ & 32 & $32 \%$ \\
\hline & $41-50$ & 28 & $28 \%$ \\
\hline & $51-55$ & 11 & $11 \%$ \\
\hline \multirow{4}{*}{ BMI $\left(\mathrm{kg} / \mathrm{m}^{2}\right)$} & $35-39.9$ & 5 & $5 \%$ \\
\hline & $40-44.9$ & 29 & $29 \%$ \\
\hline & 45-49.9 & 38 & $38 \%$ \\
\hline & $50-55$ & 28 & $28 \%$ \\
\hline \multirow{2}{*}{ Special habits } & Smoker & 14 & $14 \%$ \\
\hline & Nonsmoker & 86 & $86 \%$ \\
\hline \multirow{4}{*}{ Comorbidities } & DM & 9 & $9 \%$ \\
\hline & HTN & 13 & $13 \%$ \\
\hline & Asthma & 3 & $3 \%$ \\
\hline & NON & 75 & $75 \%$ \\
\hline \multirow{2}{*}{ H-pylori } & + ve & 26 & $26 \%$ \\
\hline & -ve & 74 & $74 \%$ \\
\hline
\end{tabular}

\section{B. According to Sex}

There were 85 females and 15 males (Table 2).

Table 2: Sex distribution

\begin{tabular}{lcc}
\hline & Female & Male \\
\hline No. of patients & 85 & 15 \\
Percentage & $85 \%$ & $15 \%$ \\
\hline
\end{tabular}

\section{According to Age}

The age of the patients ranged between 18 and 55 years with mean of 37.9 years old years for all patients. With males ranging between 26 and 55 years with mean of 41.8 years and females ranging between 18 and 52 years with mean of 37.3 years (Table 3). 
Table 3: Age distribution between males and females

\begin{tabular}{lccc}
\hline Age & Female & Male & Total \\
\hline Range of age (Years) & $18-52$ & $26-55$ & $18-55$ \\
Mean(years) & 37.3 & 41.8 & 37.9 \\
\hline
\end{tabular}

\section{According to Body Mass Index (BMI)}

The Body Mass Index of those morbidly obese patients included in this study was ranging from
37.9 to $55 \mathrm{~kg} / \mathrm{m} 2$ (Median BMI for female was 48.3 $\mathrm{kg} / \mathrm{m} 2$ and for male was $46.9 \mathrm{~kg} / \mathrm{m} 2$ ) with a median for all patients is $47.8 \mathrm{~kg} / \mathrm{m} 2$ (Table 4).

Table 4: BMI distribution between males and females

\begin{tabular}{lccc}
\hline BMI & Female & Male & Total \\
\hline Range $\left(\mathbf{K g} / \mathbf{m}^{2}\right)$ & $39-55$ & $37.9-53.2$ & $37.9-55$ \\
Median $\left(\mathbf{K g} / \mathbf{m}^{2}\right)$ & 48.3 & 46.9 & 47.8 \\
\hline
\end{tabular}

\section{E. According to Special habits}

The majority of patients were non-smokers (86\%). While percentage of smoker patients was (14\%) (Table 5).

Table 5: Special habits distribution

\begin{tabular}{lcc}
\hline & Smokers & Non-smokers \\
\hline No. of patients & 14 & 86 \\
Percentage of patients & $14 \%$ & $86 \%$ \\
\hline
\end{tabular}

\section{F. According to Comorbidities}

$(75 \%)$ of patients had no comorbidities while $(9 \%)$ were diabetic, $(13 \%)$ were hypertensive and $(3 \%)$ were asthmatic (Table 6).

Table 6: Comorbidities distribution

\begin{tabular}{lcc}
\hline Type of surgery & $\begin{array}{c}\text { No. of } \\
\text { Patients }\end{array}$ & Percentage \% \\
\hline DM & 9 & $9 \%$ \\
HTN & 13 & $13 \%$ \\
Asthma & 3 & $3 \%$ \\
No Comorbidities & 75 & $75 \%$ \\
\hline
\end{tabular}

\section{G. According to preoperative H. Pylori} infection

Searching for $\mathrm{H}$-pylori antigen in stool before surgery $(74 \%)$ rendered negative where $(26 \%)$ were marked positive by the test (Table 7).

Table 7: Preoperative H. Pylori infection distribution

\begin{tabular}{lcc}
\hline & Positive & Negative \\
\hline No. of patients & 26 & 74 \\
Percentage of patients & $26 \%$ & $74 \%$ \\
\hline
\end{tabular}

\section{H. According to type of surgery}

All patients among our study were laparoscopically operated. The majority of cases underwent Laparoscopic Sleeve Gastrectomy LSG (71\%), Laparoscopic Monogastric Bypass surgery MGB (24\%) and Roux-en-Y Gastric Bypass RYGB (5\%) (Table 8).

Table 8: Type of surgery

\begin{tabular}{lcc}
\hline Type of surgery & $\begin{array}{c}\text { No. of } \\
\text { Patients }\end{array}$ & $\begin{array}{c}\text { Percentage } \\
\%\end{array}$ \\
\hline $\begin{array}{l}\text { Laparoscopic Sleeve } \\
\text { Gastrectomy }\end{array}$ & 71 & $71 \%$ \\
$\begin{array}{l}\text { Laparoscopic } \\
\text { Minigastric Bypass }\end{array}$ & 24 & $24 \%$ \\
$\begin{array}{l}\text { RouX-en-Y Gastric } \\
\text { Bypass }\end{array}$ & 5 & $5 \%$ \\
\hline
\end{tabular}

I. Distribution of patients according to percentage of Postoperative Vomiting

A large percentage of patients (39\%) developed postoperative vomiting during the first 48 postoperative hours. While $(4 \%)$ of cases who continued to suffer from vomiting during the postoperative 2 months (Table 9).

Table 9: Distribution of percentage of Postoperative Vomiting

\begin{tabular}{lcc}
\hline Time of Vomiting & $\begin{array}{c}\text { No. of } \\
\text { Patients }\end{array}$ & $\begin{array}{c}\text { Percentage } \\
\%\end{array}$ \\
\hline $\begin{array}{l}\text { Vomiting during the } \\
\text { first 48 postoperative } \\
\text { hours }\end{array}$ & 39 & $39 \%$ \\
$\begin{array}{l}\text { Vomiting during } \\
\text { the postoperative 2 } \\
\text { months }\end{array}$ & 4 & $4 \%$ \\
\hline
\end{tabular}


J. Distribution of patients according to management of persistent Vomiting

$4 \%$ of patients had persistent Vomiting during the postoperative two months. Endoscopic treatment was successful for 1 of the 4 patients (25\%) after balloon dilatation and insertion of a stent. 3 of the 4 patients $(75 \%)$ required surgical intervention (Table 10).

Table 10: Distribution of management of persistent Vomiting

\begin{tabular}{lcc}
\hline $\begin{array}{l}\text { Management of } \\
\text { persistent Vomiting }\end{array}$ & $\begin{array}{c}\text { No. of } \\
\text { Patients } \\
\text { (4) }\end{array}$ & $\begin{array}{c}\text { Percentage } \\
\%\end{array}$ \\
\hline $\begin{array}{l}\text { Endoscopic } \\
\text { intervention } \\
\begin{array}{l}\text { Surgical } \\
\text { intervention }\end{array}\end{array}$ & 1 & $25 \%$ \\
\hline
\end{tabular}

Cases that suffered from persistent postoperative vomiting without improvement with antiemetic medical treatment and were in need for further management as the following:

Case 1: underwent LSG with delayed recovery complained of recurrent episodes of postoperative vomiting. UGI contrast study showed long segment of stricture at the level of incisura angularis. Thus, it is converted to MGB.

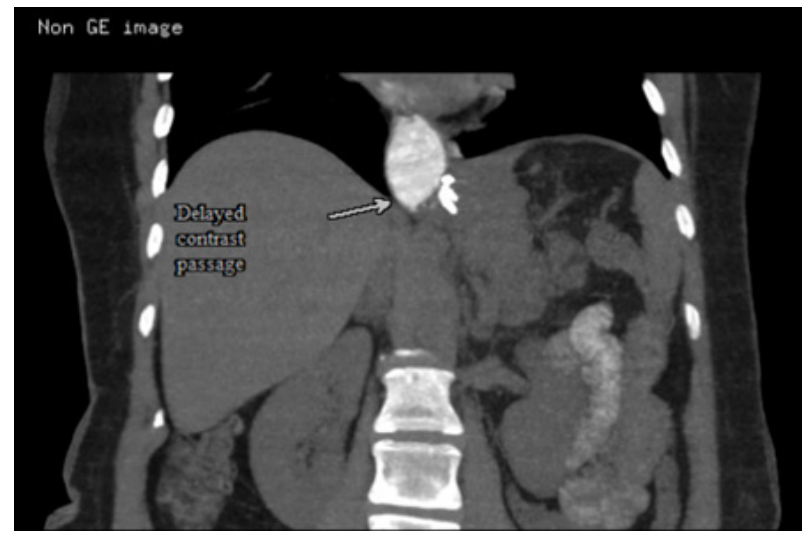

Fig 1: Stricture complicating LSG with delayed contrast passage.

Case 2: Underwent LSG and showed obstructive symptoms with intolerable postoperative vomiting and signs of dehydration. The patient was diagnosed as kinking with help of UGI endoscopy. The case was managed surgically with laparoscopic adhesiolysis and gastropexy.

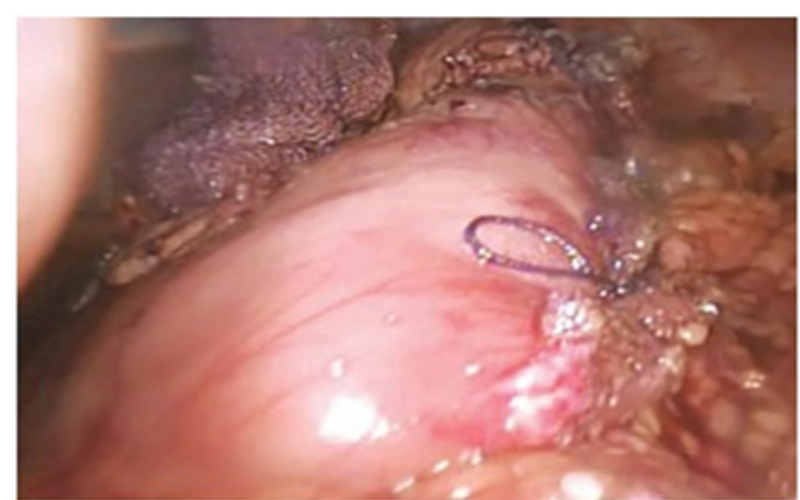

Fig 2: Laparoscopic Gastropexy.

Case 3: underwent LSG suffered from persistent postoperative vomiting and progressive dysphagia to fluids. With UGI endoscopy, the case had gastric outlet stenosis. Therefore, the case was managed endoscopically by dilation with stent insertion.
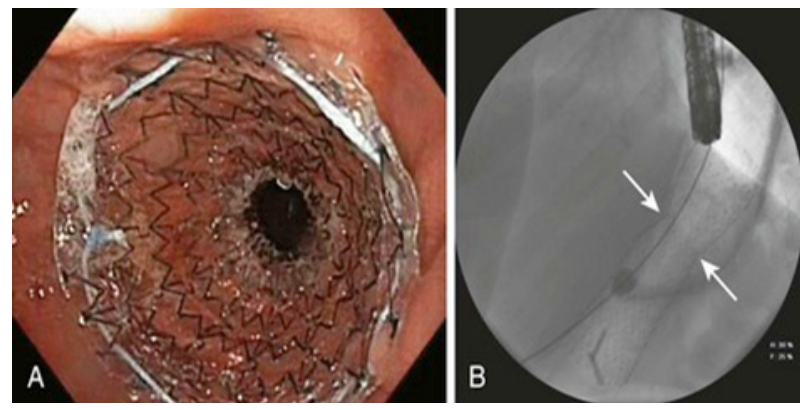

Fig 3: Endoscopic stent insertion.

Case 4: Underwent MGB suffered from persistent postoperative reflux symptom and intolerable bilious vomiting. The case failed to improve to medical treatment with Cholestyramine (bile acid sequestrant) and Aprepitant. UGI endoscopy showed pan gastritis and esophagitis. A biopsy was taken and revealed biliary gastritis. So, it was treated surgically with conversion to RYGB.

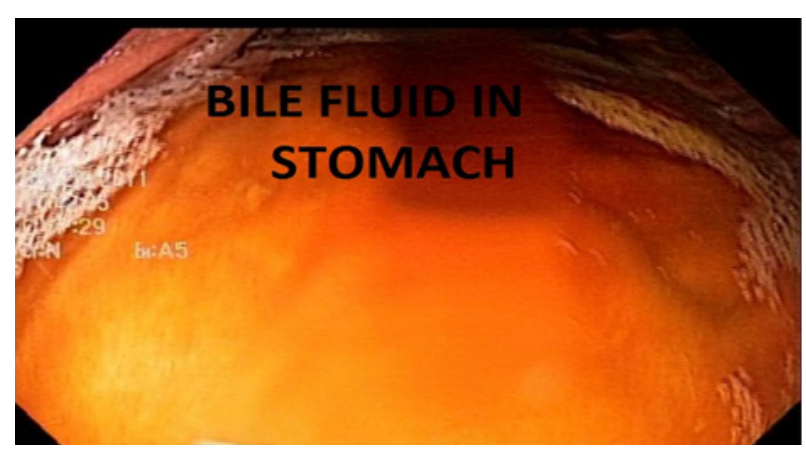

Fig 4: Biliary gastritis. 


\section{Discussion}

Obesity is a global pandemic in various nations. It increases the risk for developing comorbidities as diabetes mellitus, hypertension and ischemic heart disease. Individuals with BMI $\geq 40 \mathrm{~kg} /$ $\mathrm{m} 2$ and those with BMI $>35 \mathrm{~kg} / \mathrm{m} 2$ with obesity related comorbidities; who failed diet, exercise, and drug therapy, should be considered for bariatric surgery. Bariatric operations are either: Restrictive, malabsorptive, or a combination of both procedures (e.g.; Roux-en-Y Gastric bypass surgery). ${ }^{12}$

Postoperative Vomiting is often triggered by different things, such as anxiety, illness, perioperative stimuli, anesthesia, drug interactions, marginal ulceration, staple line failure, stenosis/obstruction, gastrogastric fistula, gastrojejunostomy anastomotic stricture, pouch dilation, and pouch gastritis. ${ }^{13}$

In our study 100 patients who underwent LBS were included in this retrospective clinical trial over a 6 months period to evaluate the percentage of Postoperative Vomiting occurrence after surgery for two months of follow up. The majority of patients are females in the late thirties. $26 \%$ were marked positive after searching for $\mathrm{H}$-pylori antigen in stool. The study declared a high percentage of postoperative vomiting (39\%) of cases within the first 48 hours of operation. Most of them showed a significant improvement with the use of centrally acting antiemetic drug. $4 \%$ of patients suffered from persistent vomiting during the postoperative 2 months; investigated by virtual gastroscopy, UGIE and CT scan with contrast. One of them suffered from moderate stenosis who underwent balloon dilatation with stent insertion. The other three cases were managed surgically with conversion to Roux-en-Y gastric bypass, Mini gastric bypass or Gastropexy.

Various research groups of investigators studied the anatomic and physiologic effects of LBS and postulated their effect on GERD. Using manometry, it was priorly revealed and displayed that the pressure in the lower oesophageal sphincter was reduced after laparoscopic sleeve gastrectomy, could cause reflux symptoms and esophagitis. ${ }^{14}$

Besides oesophageal manometry might be a useful criterion in deciding whether to conduct laparoscopic bariatric surgery. The lack of gastric compliance and emptying and the blunting of the angle of His inherent in LSG at 1 year were responsible for the increase GERD symptoms at 1 year after LBS. Increase in gastric compliance and clearance after 3 years caused relief of GERD symptoms at 3 years. Barium swallow after 3 years showed restoration of the angle of His and decrease in GERD. ${ }^{15}$

\section{A previous similar research study similar in approach}

and methodology to the current research observed that after a median follow-up of 13 months on 74 cases declared that an increase in the incidence of upper GI symptoms was observed in that $91.9 \%$ $(68 / 74)$ of the patients complained of symptoms compared with $47.3 \%(35 / 74)$ before surgery. Dyspepsia was the main complaint in $59.4 \%(44 / 74)$ of the patients. ${ }^{16}$

Fernandes et al. research team of investigators statistically analysed the data of 613 study subjects undergoing UGIE in a retrospective research study, in which all cases had an indication for bariatric surgery. $77.8 \%$ female, with mean age of $46.5 \pm 11.6$ years and mean BMI of $44.7 \pm 4.2 \mathrm{~kg} / \mathrm{m} 2$. UGIE showed at least one abnormality in 345 patients $(56.3 \%)$. Oesophageal, gastric, and duodenal abnormalities were reported in $22.2,41.8$, and $11.4 \%$ of patients, consecutively. ${ }^{16-19}$

In accordance with his results, abnormal findings in UGIE was found in 10 to $90 \%$ of patients across studies, so many authors limited endoscopy to patients complaining of gastrointestinal symptoms. This is inadequate, as many studies found pathologic endoscopic findings in asymptomatic patients. Other authors have abandoned routine UGE before surgery. There are no sufficient data to know which endoscopic findings should delay or contraindicate surgery. Fernandes S. et al., found gastric and duodenal ulcers to be the only significant predictors of postoperative complications. ${ }^{16}$

A prior research team of investigators compared $\mathrm{H}$. pylori presence pre and postoperatively, observed the prevalence of $\mathrm{H}$. pylori in the population undergoing bariatric surgery, and studied the impact of $\mathrm{H}$. pylori screening and eradication carried out by some surgeons. When observing $\mathrm{H}$. pylori infections before and after LBS, it was clear that its presence in symptomatic patients who underwent UGIE was high $(49.7 \%)$. Furthermore, since by the time of surgery $\mathrm{H}$. pylori was only seen in $7.8 \%$ of patients, this indicates that preoperative UGIE does help in eradicating the infection, especially in symptomatic patients. $93.6 \%$ of the $\mathrm{H}$. pylori-positive patients who took triple therapy were negative by the time of surgery. In contrast, more than half of the patients who were positive preoperatively and did not take triple therapy remained positive at the time of surgery. ${ }^{20}$

Another research team of investigators compared the effectiveness of granisetron either alone or in combination with droperidol or dexamethasone, for the prevention of post-operative nausea and vomiting in patients undergoing LBS. The combination of granisetron and dexamethasone decreases postoperative vomiting. There is no study that compares the effects of granisetron and 
its combinations for the prevention of postoperative vomiting in patients undergoing LBS. ${ }^{19}$

Another previous prospective, randomized, double blind and placebo-controlled research study to compare the antiemetic effect of the prophylactic administration of either granisetron alone, and in combination with droperidol or dexamethasone for preventing postoperative vomiting in patients undergoing LBS. Furthermore, prior research groups revealed that granisetron in combination with dexamethasone is better than granisetron alone or in combination with droperidol for decreasing the incidence of postoperative vomiting in patients undergoing LBS. ${ }^{19}$

Therneau et al. research team of investigators conducted a research study to review episodes of Postoperative Vomiting during 48 postoperative hours after laparoscopic bariatric surgery on 338 study subjects administered triple antiemetic, of which 172 cases (51\%) also received aprepitant. Rates of Postoperative Vomiting in the post anaesthesia care unit among patients with and without aprepitant therapy were 11 versus. $17 \%$. Addition of aprepitant to a multimodal antiemetic prophylactic regimen could be linked with a statistically significant reduction of Postoperative Vomiting during early recovery period. The high postoperative vomiting rate in the first 48 postoperative hours is suggestive that introduction of centrally acting antiemetic (aprepitant) prophylactic treatment may be desirable. ${ }^{18}$

\section{Conclusions}

Results reveal and display that postoperative vomiting after Laparoscopic Bariatric Surgeries (LBS) represents a considerable complication which occurs commonly. Vomiting of medical causes responds well to centrally acting antiemetic. Endoscopic and surgical interventions were required for technical problems. Further research studies have to be performed in a multicentric fashion on a larger number of cases to confirm results of the current study.

\section{References}

1. Mathus-Vliegen $E M H$, Basdevant $A$, Finer $N$, Hainer V, Hauner H, Micic D, Tsigos C: Prevalence, pathophysiology, health consequences and treatment options of obesity in the elderly: A guideline. Obesity Facts. 2012; 5(3): 460-483.

2. Coppa GF, McMullen H, Geiss A, Choy C: Laparoscopic Adjustable Gastric Banding. In Chassin's Operative Strategy in General Surgery. 2014: 367-372.

3. Martinovski $M$, Navratil $A$, Zeni $T$, Jonker $M$, Ferraro J, Albright J, Cleary R: Minimally Invasive
Roux-En-Y Gastric Bypass versus Biliopancreatic Diversion with Duodenal Switch: Results from the Metabolic and Bariatric Surgery Accreditation and Quality Improvement Program (MBSAQIP): Surgery for Obesity and Related Diseases. 2017; 13(10): S18.

4. Dayyeh BKA, Rajan E, Gostout C]: Endoscopic sleeve gastroplasty: A potential endoscopic alternative to surgical sleeve gastrectomy for treatment of obesity. Gastrointestinal Endoscopy. 2013; 78(3): 530-535.

5. De Angelis F, Abdelgawad M, Rizzello M, Mattia $C$ and Silecchia G: Perioperative hemorrhagic complications after laparoscopic sleeve gastrectomy: Four-year experience of a bariatric center of excellence. Surgical Endoscopy. 2017; 31(9): 3547-3551.

6. Choi SH, Kasama K: Bariatric and Metabolic Surgery, (C) Springer-Verlag Berlin Heidelberg. DOI 10.1007/978-3-642-35591-2_1. 2014.

7. Casella G, Soricelli E, Genco A, Redler A, Basso N: Laparoscopic Sleeve Gastrectomy. In Minimally Invasive Bariatric and Metabolic Surgery. $2015: 175-185$.

8. Rebibo L, Hakim S, Dhahri A, Yzet T, Delcenserie $\mathrm{R}$, Regimbeau JM: Gastric stenosis after laparoscopic sleeve gastrectomy: Diagnosis and management. Obesity Surgery. 2016; 26(5): 995-1001.

9. Alaeddine $M H$, Shamseddine GA, Safadi BY: Laparoscopic sleeve gastrectomy. In: Operative Dictations in General and Vascular Surgery. 2017: 131-133.

10. Bradley JF, Ross SW, Christmas AB, Fischer PE, Sachdev G, Heniford BT, Sing RF: Complications of bariatric surgery: The acute care surgeon's experience. The American Journal of Surgery. 2015; 210(3): 456-461.

11. Burdan F, Rozylo I, Szumilo J, et al: Anatomical classification of the shape and topography of the stomach. Surg Radiol Anat. 2012; 34(2): 171-178.

12. Cabrera A, Vives $M$, Molina A, París $M$, Raga $E$, Sánchez A, Del Castillo D: Gastric plication and sleeve gastrectomy in an experimental model of obesity: New insights into weight loss, intake and metabolic results. Obesity Surgery. 2018: $1-9$.

13. Chen KN: Managing complications I: Leaks, strictures, emptying, reflux, and chylothorax. 
Journal of Thoracic Disease. 2014; 6(3): S355.

14. Deem ME, Sutton DS, Gifford HS, Andreas $\mathrm{BH}$, French RG: Obesity treatment tools and methods. United States Patent US. 2013; Pat No. $6,558,400$.

15. Carabotti M, Silecchia G, Greco F, et al: Impact of laparoscopic sleeve gastrectomy on upper gastrointestinal symptoms. Obes Surg. 2013; (10): 1551-1557.

16. Fernandes SR, Meireles LC, Carrilho-ribeiro $\mathrm{L}$, Velosa J: The role of routine upper gastrointestinal endoscopy before bariatric surgery. 2016; 26(9): 2105-2110.

17. Peromaa-Haavisto $P$, Victorzon $M$ : Is routine preoperative upper GI endoscopy needed prior to gastric bypass? Obes Surg. 2013; 23(6): 736739.

18. Therneau IW, Martin EE, Sprung J, Kellogg TA, Schroeder DR, Weingarten TN: The role of aprepitant in prevention of postoperative nausea and vomiting after bariatric surgery. Obesity Surgery. 2018; 28(1): 37-43.

19. Carter R, Mouralidarane A, Ray S, Soeda J, Oben $\mathrm{J}$ : Recent advancements in drug treatment of obesity. Clinical Medicine. 2012; 12(5): 456460.

20. Almazeedi S, Al-Sabah S, Alshammari D, et al: The Impact of Helicobacter pylori on the Complications of Laparoscopic Sleeve Gastrectomy. Obes Surg. 2014; 24:412-415. 